\title{
Group A Streptococcus disease in Hong Kong children: an overview
}

\author{
Theresa NH Leung, KL Hon *, Alexander KC Leung
}

\section{A B S T R A C T}

Group A $\beta$-haemolytic Streptococcus or Streptococcus pyogenes is a gram-positive coccus that tends to grow in chains. Streptococcus pyogenes is the cause of many important human diseases, ranging from pharyngitis and mild superficial skin infections to lifethreatening systemic diseases. Infections typically begin in the throat or skin. Mild Streptococcus pyogenes infections include pharyngitis (strep throat) and localised skin infections (impetigo). Erysipelas and cellulitis are characterised by multiplication and lateral spread of Streptococcus pyogenes in deep layers of the skin. Streptococcus pyogenes invasion and fascial involvement can lead to necrotising fasciitis, a life-threatening condition. Scarlet fever is characterised by a sandpaper-like rash in children with fever and is caused by a streptococcal toxin. Severe infections that lead to septicaemia or toxic shock syndrome are associated with high mortality.

This article was published on 9 Nov 2018 at www.hkmj.org.
Autoimmune reactions cause characteristic syndromes such as rheumatic fever and nephritis. Epidemiology, disease presentation, diagnosis, and treatment of paediatric patients in Hong Kong with group A $\beta$-haemolytic Streptococcus are reviewed in this article. Streptococcus pyogenes disease is readily treatable, as the organism is invariably sensitive to penicillin. Delayed treatment of this common childhood pathogen is associated with significant mortality and morbidity.

Hong Kong Med J 2018;24:593-601
DOI: 10.12809/hkmj187275
1 TNH Leung, FRCPCH (UK), FHKAM (Paediatrics)
${ }^{2}$ KL Hon *, MD, FAAP
${ }^{3}$ AKC Leung, FRCP (UK \& Irel), FRCPCH
1 Department of Paediatrics and Adolescent Medicine, The University of
Hong Kong, Pokfulam, Hong Kong
2 Department of Paediatrics, The Chinese University of Hong Kong,
Shatin, Hong Kong
${ }^{3}$ Department of Paediatrics, Alberta Children's Hospital, The University of
Calgary, Calgary, Alberta, Canada
* Corresponding author: ehon@hotmail.com

\section{Introduction}

Group A $\beta$-haemolytic Streptococcus (GABHS) is a gram-positive, non-motile, non-spore-forming coccus that tends to grow in chains. It produces a large variety of extracellular enzymes and toxins and has $\beta$-haemolytic properties. ${ }^{1}$ Streptococcus pyogenes is the most important species of GABHS, causing many human diseases. The terms GABHS and $S$ pyogenes are often used synonymously in the literature. ${ }^{2}$ Infections with GABHS typically begin in the throat or skin. The spectrum of infections ranges from mild pharyngitis (strep throat) and localised skin infections (impetigo) to moderate-to-severe manifestations in the forms of scarlet fever, pneumonia, bacteraemia, erysipelas, cellulitis, and life-threatening conditions such as necrotising fasciitis and toxic shock syndrome. Immune-mediated clinical conditions linked to GABHS infection include rheumatic fever, poststreptococcal glomerulonephritis, arthritis, and paediatric autoimmune neuropsychiatric disorders associated with streptococcal infections (PANDAS). The manifestations of acute GABHS infection mostly affect schoolchildren. There has been a surge of GABHS in Hong Kong and worldwide in recent years, and its epidemiology and clinical manifestations in Hong Kong children are reviewed in this article. A PubMed search for references was performed using the MeSH terms "Streptococcus pyogenes" or "group A Streptococcus" and "Hong Kong", limited to 'human', with no filters for article type and publication time. This discussion is based on, but not limited to, the search results.

\section{Epidemiology of group A $\beta$ - haemolytic Streptococcus}

Infections related to GABHS have long been described throughout history, but Streptococcus was not discovered to be the causative organism of erysipelas and wound infection until 1847. It was further named Streptococcus pyogenes (pyo = pus, genes $=$ forming) in 1884 after the bacteria were found in suppurative conditions. ${ }^{3}$ Scarlet fever was first identified in the medical literature in 1675 and named "scarlatina". Before the era of antibiotics, epidemics of scarlet fever leading to high mortality had been described for centuries. ${ }^{3}$ Despite significant improvements to socioeconomic conditions over the past 50 years, $S$ pyogenes still remains one of the top ten infective causes contributing to global childhood 


\section{A組B-溶血性鏈球菌香港兒童患者概述}

梁銀河、韓錦倫、梁國柱

$A$ 組 $B$-溶血性鏈球菌或化膿性鏈球菌是革蘭氏陽性球菌，傾向以鏈狀 生長。化膿性鏈球菌可引致多種重要人類疾病, 由咽炎和輕度淺表皮 膚感染到危及生命的全身性疾病。感染通常始於咽喉或皮膚。輕度化 膿性鏈球菌感染包括咽炎（鏈球菌性咽喉炎）和局部皮膚感染（膿 皰病）。化膿性鏈球菌在皮膚深層增殖和側向擴散引致丹毒和蜂窩織 炎。化膿性鏈球菌侵襲筋膜可導致危及性命的壞死性筋膜炎。兒童患 猩紅熱的特徵包括發燒和砂紙樣皮疹, 是由鏈球菌毒素引起的, 可導 致敗血症或中毒性休克綜合徵, 嚴重感染死亡率高。與化膿性鏈球菌 感染有關的自身免疫反應也可引起如風濕熱和腎炎等特徵。本文回顧 $A$ 組 $B$-溶血性鏈球菌香港兒童患者的流行病學、疾病表現、診斷和治 療的研究。化膿性鏈球菌病因對青徽素敏感易於治療, 但延遲治療這 種常見的兒童病原體, 是導致顯著死亡率和發病率的相關因素。 mortality. ${ }^{4,5}$ A review published by the World Health Organization (WHO) in 2005 estimated that approximately 18.1 million people had serious GABHS-related disease, including rheumatic heart diseases, post-streptococcal glomerulonephritis, and over 650000 cases of invasive diseases. The WHO review identified 1.78 million new cases of serious disease and over 500000 deaths each year. In addition, the review indicated over 111 million new cases of streptococcal pyoderma and 616 million cases of GABHS pharyngitis each year. ${ }^{6}$

The prevalence of disease varies with age, time, season, and geographic location. Group A $\beta$ haemolytic Streptococcus infections predominantly affect children aged 5 to 15 years. ${ }^{7,8}$ With the wide range of diseases caused by GABHS and the lack of standard surveillance criteria, accurate data on its associated disease burden are limited. Over the years, reporting of scarlet fever and invasive GABHS diseases has become a statutory requirement in many countries. ${ }^{4}$ Scarlet fever has been a statutorily notifiable disease in Hong Kong since 1940, with its associated disease activity closely monitored by the Centre for Health Protection. However, reporting of invasive GABHS diseases not presenting as scarlet fever by individuals and institutions is voluntary. ${ }^{9}$

\section{Scarlet fever outbreak}

The incidence of scarlet fever has remained low in developed countries, in which health care and socioeconomic conditions have improved since the late 20th century. However, in 2011, a surge of scarlet fever was observed in East Asia, including in Hong Kong, China, South Korea, and Vietnam.,10-12 Recently, a similar upsurge of reports has occurred in the United States, England, and European countries. ${ }^{13}$ In Hong Kong, there was an outbreak of 1535 total cases (21.7 cases per 100000 population) of scarlet fever in 2011. This was almost 10 times the average annual incidence throughout the previous two decades, during which annual incidence ranged from 0.0351 to 3.37 cases per 100000 population. ${ }^{14,15}$ During the outbreak, the age distribution was similar to that in past reports, with the majority of cases in children aged $<10$ years and a median age of 6 years. ${ }^{15}$ Two deaths were reported. The annual incidence has since remained high, with 1100 to 1500 cases reported in subsequent years, and there was a further increase to 2353 cases reported in 2017 (Fig). ${ }^{16}$ Epidemiological analysis of reported cases in Hong Kong from 2005 to 2015 indicated that the surge was more apparent among children aged $<5$ years, with the highest incidence at age 3 to 5 years. There was a 5 -fold increase of annual incidence in children aged $<5$ years, from 3.3 per 10000 population in 2005 to 2010 to 18.1 per 10000 population in 2012 to $2015 .{ }^{17}$

The reason for the worldwide surge of scarlet fever is still mysterious. In the 2011 Hong Kong outbreak, the emergence of scarlet fever $S$ pyogenes emm 12 clones was associated with toxin acquisition and multidrug resistance, which could have contributed to the outbreak. ${ }^{18,19}$ Environmental alterations and host immunity are other possible factors. Similar seasonal trends were observed in the pre-surge (2005-2010) and post-surge (20112015) periods, with troughs in early September and rises after school holidays, with peaks in January. There was a slight bimodal elevation in June during the post-surge period. Reductions by $30 \%$ to $40 \%$ of cases after school holiday weeks were observed during both periods. ${ }^{17}$ Meteorological factors including humidity, rainfall, and temperature were found to be associated with scarlet fever, but these factors sometimes had opposite valences at different periods and in different places. ${ }^{20}$

\section{Clinical manifestations of group A $\beta$-haemolytic Streptococcus infection in children}

Clinical presentations of streptococcal infections vary according to bacterial virulence factors and individual host response. In 1993, an informal group of microbiologists, clinicians, and epidemiologists formed a working group on severe streptococcal infections and classified GABHS infections into five groups ${ }^{21}$ : streptococcal toxic shock syndrome, invasive infections, scarlet fever, non-invasive infections (throat and skin infections), and nonsuppurative sequelae.

\section{Streptococcal toxic shock syndrome}

Streptococcal toxic shock syndrome is a severe form 


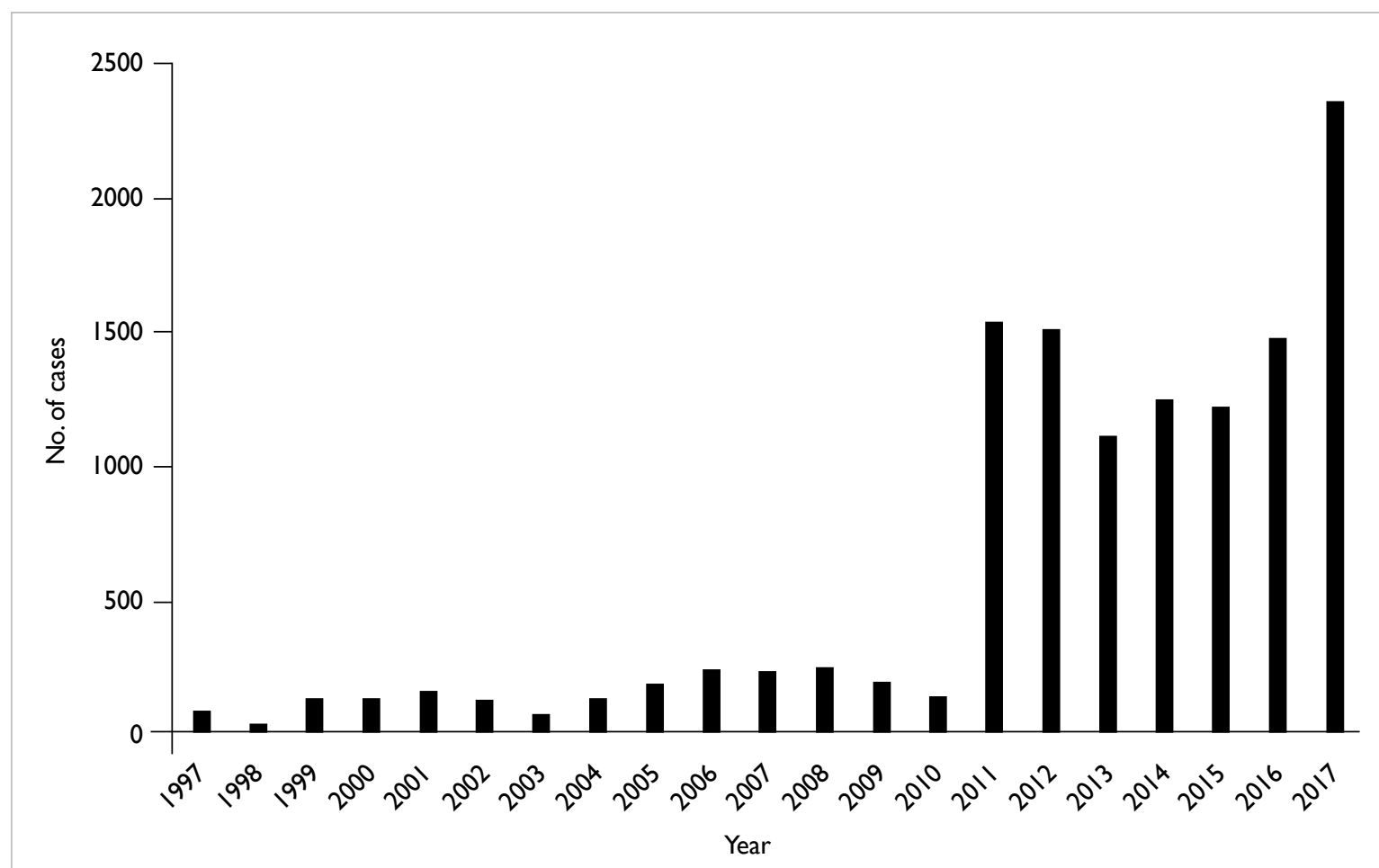

FIG. Annual reports of scarlet fever in Hong Kong (1997-2017) ${ }^{16}$

of streptococcal infection due to toxin-mediated acute illness. Patients present with fever, rash, hypotension, and organ failure, and it can be lifethreatening. ${ }^{9}$ Endotoxins produced by $S$ pyogenes are associated with disease invasiveness. Streptococcal pyrogenic exotoxin $\mathrm{A}$ and streptococcal superantigen, are two of the superantigens that stimulate $\mathrm{T}$-cell response and induce cytokinemediated inflammatory reactions, thereby leading to shock and organ dysfunction. Some exotoxins can also induce shock through non-cytokinemediated mechanisms. Streptococcal pyrogenic exotoxin $B$ has been shown to release bradykinins, causing vasodilation, while streptolysin $\mathrm{O}$ can lead to dysfunction of cardiomyocytes. ${ }^{22}$ Mortality of streptococcal toxic shock syndrome in children has been reported to be $5 \%$ to $10 \%{ }^{23}$

Streptococcal toxic shock syndrome was defined by the working group on severe streptococcal infections according to the following criteria: (1) identification of GABHS in sterile sites as definite cases or in non-sterile sites as probable cases and (2) the presence of features of shock and organ dysfunction. ${ }^{21}$ Streptococcal toxic shock syndrome is characterised by the co-existence of shock and organ dysfunction in the early course of the disease. In certain cases, organ dysfunction can precede hypotension. Septic shock leading to organ dysfunction differentiates it from other invasive GABHS infections. Streptococcal toxic shock syndrome is rarely associated with pharyngitis; rather, it more commonly follows skin infections. In $50 \%$ of cases, no obvious bacterial portal of entry can be identified. ${ }^{22}$ Diagnosis is often delayed, as patients present with non-specific symptoms of fever, vomiting, and abdominal pain without localising signs in early stage of illness. The clinical course can progress rapidly to shock and organ dysfunction, and the typical signs of deepseated infection or necrotising fasciitis usually become obvious in later stages. Streptococcal toxic shock syndrome can occur with coinfections of viral infections such as varicella and influenza B infections. Use of nonsteroidal anti-inflammatory drugs has been reported to be associated with severe necrotising fasciitis, possibly because they mask the signs and symptoms of inflammation. ${ }^{22-25}$ The clinical course of streptococcal toxic shock syndrome can be rapidly fatal, and early recognition is very important. ${ }^{25}$ Management is mainly supportive and consists of maintenance of haemodynamic stability, with administration of fluids and inotropic medications, prompt initiation of antibiotics for infection control, and surgical intervention as indicated in cases of necrotising fasciitis. Intravenous immunoglobulin may be considered as an adjunctive therapy to neutralise superantigens, although clinical evidence regarding mortality outcomes remains controversial. $^{22,23}$ 


\section{Invasive infections}

Invasive GABHS diseases are usually defined as clinical diseases associated with identification of $S$ pyogenes in sterile sites including blood, cerebrospinal or pleural fluids, deep wounds, and muscles. Before the introduction of antibiotics, bacteraemia was not uncommon, especially at extremes of age. In children, upper respiratory infections, varicella infections, and skin wounds are predisposing factors for invasive GABHS infections. Pneumonia usually starts as streptococcal pharyngitis, with $40 \%$ to $50 \%$ of cases complicated by empyema. Mortality is generally low with the appropriate use of antibiotics and management of empyema.

\section{Scarlet fever}

Scarlet fever is a clinical syndrome associated with $S$ pyogenes pharyngitis or, less commonly, skin and soft tissue infections (the latter is known as "surgical" scarlet fever). It typically presents as abrupt onset of fever, sore throat, beefy red pharynx, and enlarged and erythematous tonsils (with or without exudates) followed by the development of sandpaper-like erythematous skin rashes on the first to second day of the fever. ${ }^{1}$ Skin rashes often start from the trunk and spread to the limbs, being more prominent over flexures, axilla, and the groin (Pastia lines) while sparing the palms and soles. The cheeks become flushed, leaving the perioral region looking pale (circumoral pallor). The papillae of the tongue become swollen, leading to a strawberry-like appearance of the tongue. The rashes usually resolve in about 1 week, followed by desquamation of the hands and feet. ${ }^{26}$

The clinical manifestations of scarlet fever are caused by streptococcal pyrogenic exotoxins produced by certain strains of $S$ pyogenes. No single toxin but rather a combination of 11 identified exotoxins are implicated. Strains of $S$ pyogenes producing streptococcal pyrogenic exotoxins A and $\mathrm{C}$ and streptococcal superantigen have been associated with a few outbreaks. ${ }^{26}$

\section{Non-invasive infections Pharyngitis and tonsillitis}

Group A $\beta$-haemolytic Streptococcus infection is the most common bacterial cause of pharyngitis and tonsillitis both in children and adults. The typical symptoms include fever, sore throat, exudative tonsils or pharynx, and cervical lymphadenopathy. However, none of these can differentiate bacterial from viral infections. According to population studies in high-resource settings, about $4 \%$ to $10 \%$ of adults and $15 \%$ of schoolchildren had episodes of symptomatic GABHS pharyngitis each year. The rates were 5 to 10 times higher in low-resource settings. ${ }^{5}$ A meta-analysis involving studies on patients aged $<18$ years presenting with sore throat in out-patient settings showed that the pooled prevalence of positive throat swabs for GABHS was $37 \%$. The prevalence in children aged $<5$ years was lower (24\%), and it was only $5 \%$ to $10 \%$ in adults. ${ }^{7}$ In a 2000 study, patients presenting to the accident and emergency department of a Hong Kong public hospital complaining of sore throat or suspected to have acute pharyngitis had throat swabs taken for culture. ${ }^{8}$ The prevalence of GABHS pharyngitis in patients aged $\leq 14$ years was $38.2 \%$, which was similar to that in other countries, but the prevalence in patients aged $>14$ years was only $2.7 \%$. No patient was aged $<3$ years, and only one patient was aged $>60$ years. ${ }^{8}$ The findings concurred with those of previous studies, which indicated that GABHS infections are uncommon at extremes of age.

Carrier status of $S$ pyogenes in the throat is classically defined as isolation of the bacteria in subjects without clinical features of acute pharyngitis. ${ }^{27}$ Rates of $S$ pyogenes carrier status among asymptomatic schoolchildren have been reported as up to $15 \%$ to $20 \%$ in some studies. ${ }^{5,7}$ In Hong Kong, the earliest epidemiological study of GABHS in a general practice setting was reported in $1968 .{ }^{26}$ It showed carrier rates of $6.1 \%$ in the general population, $7.6 \%$ to $8.3 \%$ in schoolchildren, and $27.5 \%$ in a residential children's home. Approximately 50\% of skin infections and $29 \%$ of tonsillitis cases were due to GABHS infection..$^{28}$ With a high carrier rate of GABHS in children, it is sometimes difficult to determine in a child presenting with fever, sore throat, and a positive GABHS culture whether the symptoms are caused by a concurrent viral infection in a carrier or genuine GABHS pharyngitis. Clues in favour of GABHS pharyngitis include epidemiologic factors or clinical findings suggestive of GABHS pharyngitis, a marked clinical response to antimicrobial therapy, negative throat swab cultures between episodes of pharyngitis, and a serological response to GABHS extracellular antigens (eg, anti-streptolysin $\mathrm{O}$, anti-DNase, and antihyaluronidase). ${ }^{2,3}$ In children with recurrent pharyngitis, it may be warranted to repeat throat cultures when they are asymptomatic after treatment with antibiotics to determine their carrier status and avoid indiscriminate use of antibiotics. Eradication of bacteria by use of antibiotics in asymptomatic carriers is generally not recommended, as the risks of development of complications and transmission to others are both low in these subjects. ${ }^{27}$ The American Academy of Pediatrics Committee on Infectious Diseases suggested the following indications for treatment of carriers: (1) family history of rheumatic fever or rheumatic heart disease; (2) parental anxiety or parents considering tonsillectomy solely because of the bacterial carriage; and (3) community outbreaks of $S$ pyogenes acute pharyngitis. 


\section{Skin and soft tissue infections}

Streptococcus pyogenes can cause infections in all layers of the skin and underlying soft tissues. Superficial infections include impetigo with localised infections of the keratin layer of the epidermis. Erysipelas are characterised by multiplication and lateral spread of $S$ pyogenes in the superficial epidermis. They can spread through the lymphatic system, causing more widespread inflammation. In contrast, cellulitis results from deeper infections of subcutaneous tissues. Streptococcus pyogenes invasion and multiplication in the fascia can lead to necrotising fasciitis, which commonly involves all layers of the skin. Streptococcus pyogenes can also cause muscle infections, leading to myositis and myonecrosis. ${ }^{29}$

Impetigo is prevalent in developing countries and commonly affects young children aged 2 to 5 years. Infections are usually localised, rarely causing systemic spread. Post-streptococcal glomerulonephritis may follow impetigo caused by nephrogenic strains of GABHS, but rheumatic fever has not been found to be associated with impetigo. ${ }^{29-31}$

Cellulitis may result from infections of wounds or adjacent infections such as lymphadenitis or peritonsillar abscesses. ${ }^{32}$ Such infections may spread to involve large areas of subcutaneous tissue and be complicated by bacteraemia, toxic shock syndrome, and scarlet fever. Necrotising fasciitis is rare but has the potential to be rapidly fatal with high mortality. ${ }^{33-36}$ It may be preceded by only trivial injury or varicella infection in children. ${ }^{37}$ Early recognition with a low threshold for surgical debridement is of paramount importance in its management. ${ }^{34,36}$

\section{Immune-mediated late complications}

Streptococcus pyogenes can also cause postinfectious non-suppurative diseases. These immunemediated complications follow a small percentage of infections and include acute rheumatic fever, post-streptococcal reactive arthritis, acute poststreptococcal glomerulonephritis, guttate psoriasis, and Henoch-Schönlein purpura. ${ }^{30,38}$ Different strains of GABHS have been found to be related to acute rheumatic fever (rheumatogenic types) and acute post-streptococcal glomerulonephritis (nephrogenic types). The incidence rates of these conditions have declined dramatically in the previous half-century with the use of antibiotics. These conditions appear several weeks following initial untreated or partially treated streptococcal infections, but it is relatively common for the preceding symptoms of infection not to be recognised. The Jones diagnostic criteria for acute rheumatic fever were first established in 1944, with recent modifications by the American Heart Association (AHA). The 1992 version stated that two out of the five major criteria for GABHS infection (carditis, arthritis, Sydenham chorea, subcutaneous nodules, and erythema marginatum) or one major with two minor criteria indicate a high probability of acute rheumatic fever. ${ }^{39}$ In 2015, the AHA incorporated the use of serial echocardiography with Doppler studies to evaluate and monitor for clinical or subclinical carditis in any confirmed or suspected cases of acute rheumatic fever. Subclinical carditis refers to mitral or aortic valvulitis revealed by echocardiography/Doppler studies without the classic auscultatory findings of valvar dysfunction. ${ }^{40}$

Acute post-streptococcal glomerulonephritis is caused by immune complexes deposited in the glomerulus. The typical clinical presentation includes acute nephritic syndrome, or less commonly, nephrotic syndrome approximately 7 to 10 days after streptococcal pharyngitis and 2 to 4 weeks after skin infections. ${ }^{41}$ Prognosis in children is usually excellent, and progressive renal failure rarely occurs. The clinical condition PANDAS was described by Swedo et al in $1998 .{ }^{42}$ The diagnostic criteria for PANDAS include: (1) the presence of obsessive-compulsive disorder and/or any other tic disorders, (2) pre-pubertal onset, (3) abrupt onset and relapsing remitting symptom course, (4) a distinct association with GABHS infection, and (5) association with neurological abnormalities, such as motoric hyperactivity and choreiform movements, during exacerbations. The pathogenesis of PANDAS is uncertain but likely linked to a post-infectious autoimmune phenomenon. Treatment is mainly symptomatic, and the efficacy of immunomodulatory therapies including plasmapheresis and intravenous immunoglobulin needs further evaluation. ${ }^{43}$

\section{Laboratory diagnosis of group A $\beta$-haemolytic Streptococcus}

Laboratory diagnosis of GABHS infection is classically based on bacterial culture of clinical specimens. Bacterial colonies of Streptococcus produce rings of $\beta$-haemolysis on agar plates and appear as Gram-positive cocci in chains on microscopic examination. ${ }^{1}$ Group A $\beta$-haemolytic Streptococcus can be identified by detection of Lancefield group A antigens on the bacterial surface. Further differentiation of $S$ pyogenes from other GABHS requires pyrrolidonyl arylamidase colorimetric tests and tests of bacitracin susceptibility. Recently, more advanced automated laboratory systems based on molecular techniques have enhanced the identification of specific bacteria in blood cultures. ${ }^{44}$ The role of rapid antigen detection tests (RADTs) will be discussed in more detail below. Serology tests including anti-streptolysin $\mathrm{O}$ titre and anti-DNase are useful for diagnosis of immune-mediated late complications of GABHS infections. 
Serotyping of group A $\beta$-haemolytic Streptococcus

Group A $\beta$-haemolytic Streptococcus is serotyped according to the streptococcal $M$ protein coded by the emm gene. Since the 1990s, emm sequence typing has replaced classical $M$ protein serotyping to define GABHS strains. The epidemiology of emm strains varies geographically and temporally. A meta-analysis identified $205 \mathrm{emm}$ types worldwide, with the most common emm types being emm 1 and emm 12. There was a greater diversity of emm types in Africa and the Pacific region than in high-income countries..$^{45}$ Local and overseas studies have shown a lack of association between GABHS emm type and invasiveness or disease severity. ${ }^{46-48}$ Presumably, an increase in the prevalence of strains in the general population, host immunity, and environmental factors rather than the strains' virulence contributed to the surge of GABHS infections and severity of disease.

\section{Diagnosis and management of group A $\beta$-haemolytic Streptococcus pharyngitis}

Pharyngitis in children is commonly caused by viral infections, and GABHS is the most important bacterial cause. Throat swab culture is the gold standard for diagnosis, but the turnaround time is 2 to 3 days, limiting its utility for deciding whether antibiotics should be used for pharyngitis. The Centor score (0-4) is a 4-point clinical scale that was first reported in 1981 and is used for differentiation of GABHS pharyngitis from viral pharyngitis to decide about the use of antibiotics in adults presenting to emergency departments with sore throat. One point is scored for each of the following: fever $>38^{\circ} \mathrm{C}$, absence of coughing, presence of tonsillar exudates, and swollen and tender anterior cervical nodes. ${ }^{49}$ The modified Centor score or McIsaac score includes an age score applicable to children by adding one point for age 3 years to $<15$ years and subtracting one point for age $\geq 45$ years while keeping the minimum score as $0(0$ or -1$)$ and the maximum score as 4 ( 4 or 5)..$^{50}$ However, a large-scale validation study showed a positive predictive value of only about $35 \%$ to $55 \%$ for scores 3 and 4 and a negative predictive value of $80 \%$ for scores $\leq 2 .{ }^{51}$

Since the 1980s, commercially available RADT for detection of GABHS in throat swabs has become more widely available. Various techniques including latex agglutination, enzyme immunoassays, optical immunoassays, and molecular tests have been developed. ${ }^{52}$ In a Cochrane Review of RADT using enzyme immunoassay and optical immunoassay methods compared with throat swab cultures for diagnosis of streptococcal pharyngitis in children, the pooled sensitivity was $85.6 \%$ (95\% confidence interval $[\mathrm{CI}]=83.3-87.6 \%$, and the specificity was 95.5\% (95\% CI=94.5-96.2\%). ${ }^{53}$ In another metaanalysis identified by the review that included molecular tests, the molecular technique category had higher sensitivity and specificity than the other methods had. ${ }^{54}$ Molecular tests are not truly point-of-care tests and require specialised equipment and personnel, limiting their application in primary care settings. International guidelines on management of acute pharyngitis for adults and children make varying recommendations about the use of the Centor or McIsaac scores and microbiological tests for diagnosis and management of acute pharyngitis. ${ }^{55}$ The United States guidelines recommend performing RADT only in patients with suspicion of GABHS pharyngitis based on clinical signs and symptoms or according to the Centor score, while the United Kingdom and some guidelines from Europe do not suggest the use of RADT. ${ }^{55}$ Practice recommendations published in the Hong Kong College of Paediatricians' guidelines for management of acute pharyngitis do not recommend the use of any clinical scores for making management decisions. The guidelines suggest performing either a throat swab culture or RADT if clinical and epidemiological factors strongly suggest GABHS. Negative RADT is recommended to be confirmed by throat swab culture in these cases. ${ }^{56}$

\section{Antibiotic treatment and resistance}

Group A $\beta$-haemolytic Streptococcus is generally sensitive to penicillin and other members of the $\beta$-lactam group of antibiotics. Failure of treatment with penicillin is generally attributed to other local commensal organisms producing $\beta$-lactamase or failure to reach adequate tissue levels in the pharynx. ${ }^{57}$ In Hong Kong, macrolide-resistant strains of GABHS are common. ${ }^{48}$ According to surveillance data from the University of Hong Kong and the Public Health Laboratory Centre of the Centre for Health Protection, GABHS isolates from 2011 were all sensitive to penicillin, while more than $50 \%$ were resistant to macrolides, clindamycin, and tetracyclines. ${ }^{18,58}$ International and local management guidelines recommend either a 10-day course of penicillin or amoxicillin as firstline antibiotics for acute pharyngitis or scarlet fever due to GABHS. For patients allergic to penicillin, a narrow-spectrum cephalosporin (cephalexin, cefadroxil) is indicated, while macrolides such as azithromycin or clarithromycin are second-line options s, $56,58,59$ Oral penicillin $\mathrm{V}$ is highly sensitive, and its narrow spectrum makes it the drug of choice over amoxicillin for GABHS infection. Amoxicillin is often preferred in children because of the better taste of the suspension and its availability as chewable tablets. ${ }^{5,56}$ The Centre for Health Protection of Hong 
Kong recommends a shorter course of antibiotics of 5 to 7 days for streptococcal pharyngitis based on recent studies showing that shorter courses of antibiotics (mostly cephalosporins) are equally effective as a 10-day course of penicillins. ${ }^{60,61}$ However, for patients with positive GABHS cultures, scarlet fever, and in areas with high prevalence of rheumatic heart disease, a full 10-day course of treatment may still be needed..$^{59,60}$ Effective treatment for GABHS infection is important for control of acute infection and prevention of late immunological manifestations including rheumatic heart disease, glomerulonephritis, and PANDAS.

\section{Conclusion}

Despite the availability of antibiotics, GABHS remains an important bacterial pathogen that causes a wide variety of diseases in children. Clinicians should be familiar with the clinical features of GABHS infections to decide on the appropriate use of microbiological tests and judicious use of empirical antibiotics. Early recognition of symptoms and signs of invasive infections and serious toxinmediated conditions is the key to preventing mortality. The reasons for the recent surge of scarlet fever in Hong Kong and other parts of the world are still unclear. In addition to mandatory reporting of scarlet fever and laboratory surveillance of GABHS isolates according to current practice in Hong Kong, enhanced monitoring of severe acute GABHS infections and late immunological manifestations are important to provide a complete picture of the impact of the re-emergence of this pathogen. Further investigations on microbiological, environmental, and host factors are urgently needed to control the upsurge of GABHS infections.

\section{Author contributions}

All authors have made substantial contributions to the concept of this study, drafting of the article, and critical revision for important intellectual content.

\section{Declarations}

As an editor of the journal, KL Hon was not involved in the peer review process of the article. The authors have no conflicts of interest to disclose. All authors had full access to the data, contributed to the study, approved the final version for publication, and take responsibility for its accuracy and integrity. This paper has not been presented, published or posted before, in whole or in part.

\section{Funding/support}

This research received no specific grant from any funding agency in the public, commercial, or not-for-profit sectors.

\section{References}

1. Leung AK, Kellner JD. Group A beta-hemolytic streptococcal pharyngitis in children. Adv Ther
2004;21:277-87.

2. Wong SS, Yuen KY. Streptococcus pyogenes and reemergence of scarlet fever as a public health problem. Emerg Microbes Infect 2012;1:e2.

3. Ferretti J, Köhler W. History of streptococcal research. In: Ferretti JJ, Stevens DL, Fischetti VA, editors. Streptococcus pyogenes: Basic Biology to Clinical Manifestations. Oklahoma City, OK: University of Oklahoma Health Sciences Center; 2016. Available from: https://www.ncbi. nlm.nih.gov/books/NBK333430/. Accessed 14 Jan 2018.

4. Efstratiou A, Lamagni T. Epidemiology of Streptococcus pyogenes. In: Ferretti JJ, Stevens DL, Fischetti VA, editors. Streptococcus pyogenes: Basic Biology to Clinical Manifestations. Oklahoma City, OK: University of Oklahoma Health Sciences Center; 2016. Available from: https://www.ncbi.nlm.nih.gov/books/NBK343616/. Accessed 14 Jan 2018.

5. Sims Sanyahumbi A, Colquhoun S, Wyber R, Carapetis JR. Global disease burden of group A Streptococcus. In: Ferretti JJ, Stevens DL, Fischetti VA, editors. Streptococcus pyogenes: Basic Biology to Clinical Manifestations. Oklahoma City, OK: University of Oklahoma Health Sciences Center; 2016. Available from: https://www.ncbi. nlm.nih.gov/books/NBK333415/. Accessed 14 Jan 2018.

6. Carapetis JR, Steer AC, Mulholland EK, Weber M. The global burden of group A streptococcal diseases. Lancet Infect Dis 2005;5:685-94.

7. Shaikh N, Leonard E, Martin JM. Prevalence of streptococcal pharyngitis and streptococcal carriage in children: a meta-analysis. Pediatrics 2010;126:e557-64.

8. Wong $\mathrm{MC}$, Chung $\mathrm{CH}$. Group A streptococcal infection in patients presenting with a sore throat at an accident and emergency department: prospective observational study. Hong Kong Med J 2002;8:92-8.

9. Hon KL, Fu A, Leung TF, et al. Cardiopulmonary morbidity of streptococcal infections in a PICU. Clin Respir J 2015;9:45-52.

10. Zhang Q, Liu W, Ma W, et al. Spatiotemporal epidemiology of scarlet fever in Jiangsu Province, China, 2005-2015. BMC Infect Dis 2017;17:596.

11. Mahara G, Chhetri JK, Guo X. Increasing prevalence of scarlet fever in China. BMJ 2016;353:i2689.

12. Park DW, Kim SH, Park JW, et al. Incidence and characteristics of scarlet fever, South Korea, 2008-2015. Emerg Infect Dis 2017;23:658-61.

13. Lamagni T, Guy R, Chand M, et al. Resurgence of scarlet fever in England, 2014-16: a population-based surveillance study. Lancet Infect Dis 2018;18:180-7.

14. Luk EY, Lo JY, Li AZ, et al. Scarlet fever epidemic, Hong Kong, 2011. Emerg Infect Dis 2012;18:1658-61.

15. Lau EH, Nishiura H, Cowling BJ, Ip DK, Wu JT. Scarlet fever outbreak, Hong Kong, 2011. Emerg Infect Dis 2012;18:1700-2.

16. Centre for Health Protection, Department of Health, Hong Kong SAR Government. Statistics on communicable diseases. Available from: https://www.chp.gov.hk/en/ statistics/submenu/26/index.html. Accessed 25 Oct 2018.

17. Lee CF, Cowling BJ, Lau EH. Epidemiology of reemerging scarlet fever, Hong Kong, 2005-2015. Emerg Infect Dis 2017;23:1707-10.

18. Davies MR, Holden MT, Coupland P, et al. Emergence of scarlet fever Streptococcus pyogenes emm 12 clones in Hong Kong is associated with toxin acquisition and multidrug 
resistance. Nat Genet 2015;47:84-7.

19. Tse H, Bao JY, Davies MR, et al. Molecular characterization of the 2011 Hong Kong scarlet fever outbreak. J Infect Dis 2012;206:341-51.

20. Duan Y, Yang LJ, Zhang YJ, Huang XL, Pan GX, Wang J. Effects of meteorological factors on incidence of scarlet fever during different periods in different districts of China. Sci Total Environ 2017;581-2:19-24.

21. The Working Group on Severe Streptococcal Infections. Defining the group A streptococcal toxic shock syndrome. Rationale and consensus definition. JAMA 1993;269:390-1.

22. Stevens DL, Bryant AE. Severe group A streptococcal infections. In: Ferretti JJ, Stevens DL, Fischetti VA, editors. Streptococcus pyogenes: Basic Biology to Clinical Manifestations. Oklahoma City, OK: University of Oklahoma Health Sciences Center; 2016. Available from: https://www.ncbi.nlm.nih.gov/books/NBK333425/. Accessed 14 Jan 2018.

23. Chuang YY, Huang YC, Lin TY. Toxic shock syndrome in children: epidemiology, pathogenesis, and management. Paediatr Drugs 2005;7:11-25.

24. Lam KW, Sin KC, Au SY, Yung SK. Uncommon cause of severe pneumonia: co-infection of influenza B and Streptococcus. Hong Kong Med J 2013;19:545-8.

25. Lau SK, Woo PC, Yuen KY. Toxic scarlet fever complicating cellulitis: early clinical diagnosis is crucial to prevent a fatal outcome. New Microbiol 2004;27:203-6.

26. Wessels MR. Pharyngitis and scarlet fever. In: Ferretti JJ, Stevens DL, Fischetti VA, editors. Streptococcus pyogenes: Basic Biology to Clinical Manifestations. Oklahoma City, OK: University of Oklahoma Health Sciences Center; 2016. Available from: https://www.ncbi.nlm.nih.gov/books/ NBK333418/. Accessed 14 Jan 2018.

27. Martin J. The Streptococcus pyogenes carrier state. In: Ferretti JJ, Stevens DL, Fischetti VA, editors. Streptococcus pyogenes: Basic Biology to Clinical Manifestations. Oklahoma City, OK: University of Oklahoma Health Sciences Center; 2016. Available from: https://www.ncbi. nlm.nih.gov/books/NBK374206/. Accessed 14 Jan 2018.

28. Fischbacher E. Streptococcus pyogenes in general practice in Hong Kong. J R Coll Gen Pract 1968;16:345-52.

29. Stevens DL, Bryant AE. Impetigo, erysipelas and cellulitis. In: Ferretti JJ, Stevens DL, Fischetti VA, editors. Streptococcus pyogenes: Basic Biology to Clinical Manifestations. Oklahoma City, OK: University of Oklahoma Health Sciences Center; 2016. Available from: https://www.ncbi.nlm.nih.gov/books/NBK333408/. Accessed 14 Jan 2018.

30. Robson WL, Leung AK. Post-streptococcal glomerulonephritis: recent increase of incidence in southern Alberta. Can Fam Physician 1992;38:2883-7.

31. Robson WL, Leung AK. Post-streptococcal glomerulonephritis. Clin Nephrol 1995;43:139.

32. Leung AK, Robson WL. Childhood cervical lymphadenopathy. J Pediatr Health Care 2004;18:3-7.

33. Donaldson PM, Naylor B, Lowe JW, Gouldesbrough DR. Rapidly fatal necrotising fasciitis caused by Streptococcus pyogenes. J Clin Pathol 1993;46:617-20.

34. Leung AK, Eneli I, Davies HD. Necrotizing fasciitis in children. Pediatr Ann 2008;37:704-10.

35. Hon KL, Leung E, Burd DA, Leung AK. Necrotizing fasciitis and gangrene associated with topical herbs in an infant. Adv Ther 2007;24:921-5.
36. Cheung JP, Fung B, Tang WM, Ip WY. A review of necrotising fasciitis in the extremities. Hong Kong Med J 2009;15:44-52.

37. de Benedictis FM, Osimani P. Necrotising fasciitis complicating varicella. Arch Dis Child 2008;93:619.

38. Robson WL, Leung AK. Acute rheumatic fever and Henoch-Schönlein purpura. Acta Paediatr 2003;92:513.

39. Special Writing Group of the Committee on Rheumatic Fever, Endocarditis, and Kawasaki Disease of the Council on Cardiovascular Disease in the Young of the American Heart Association. Guidelines for the diagnosis of rheumatic fever. Jones Criteria, 1992 update. JAMA 1992;268:2069-73.

40. Gewitz MH, Baltimore RS, Tani LY, et al. Revision of the Jones Criteria for the diagnosis of acute rheumatic fever in the era of Doppler echocardiography: a scientific statement from the American Heart Association. Circulation 2015;131:1806-18.

41. Rodriguez-Iturbe B, Haas M. Post-streptococcal glomerulonephritis. In: Ferretti JJ, Stevens DL, Fischetti VA, editors. Streptococcus pyogenes: Basic Biology to Clinical Manifestations. Oklahoma City, OK: University of Oklahoma Health Sciences Center; 2016. Available from: https://www.ncbi.nlm.nih.gov/books/NBK333429/. Accessed 14 Jan 2018.

42. Swedo SE, Leonard HL, Garvey $M$, et al. Pediatric autoimmune neuropsychiatric disorders associated with streptococcal infections: clinical description of the first 50 cases. Am J Psychiatry 1998;155:264-71.

43. Esposito S, Bianchini S, Baggi E, Fattizzo M, Rigante D. Pediatric autoimmune neuropsychiatric disorders associated with streptococcal infections: an overview. Eur J Clin Microbiol Infect Dis 2014;33:2105-9.

44. Spellerberg B, Brandt C. Laboratory diagnosis of Streptococcus pyogenes (group A streptococci). In: Ferretti JJ, Stevens DL, Fischetti VA, editors. Streptococcus pyogenes: Basic Biology to Clinical Manifestations. Oklahoma City, OK: University of Oklahoma Health Sciences Center; 2016. Available from: https://www.ncbi.nlm.nih.gov/books/ NBK343617/. Accessed 14 Jan 2018.

45. Steer AC, Law I, Matatolu L, Beall BW, Carapetis JR. Global emm type distribution of group A streptococci: systematic review and implications for vaccine development. Lancet Infect Dis 2009;9:611-6.

46. Rogers S, Commons R, Danchin $\mathrm{MH}$, et al. Strain prevalence, rather than innate virulence potential, is the major factor responsible for an increase in serious group $\mathrm{A}$ Streptococcus infections. J Infect Dis 2007;195:1625-33.

47. Ho PL, Johnson DR, Yue AW, et al. Epidemiologic analysis of invasive and noninvasive group A streptococcal isolates in Hong Kong. J Clin Microbiol 2003;41:937-42.

48. Chan JC, Chu YW, Chu MY, Cheung TK, Lo JY. Epidemiological analysis of Streptococcus pyogenes infections in Hong Kong. Pathology 2009;41:681-6.

49. Centor RM, Witherspoon JM, Dalton HP, Brody CE, Link $\mathrm{K}$. The diagnosis of strep throat in adults in the emergency room. Med Decis Making 1981;1:239-46.

50. McIsaac WJ, White D, Tannenbaum D, Low DE. A clinical score to reduce unnecessary antibiotic use in patients with sore throat. CMAJ 1998;158:75-83.

51. Fine AM, Nizet V, Mandl KD. Large-scale validation of the Centor and McIsaac scores to predict group A streptococcal pharyngitis. Arch Intern Med 2012;172:847- 
52.

52. Leung AK, Newman R, Kumar A, Davies HD. Rapid antigen detection testing in diagnosing group A betahemolytic streptococcal pharyngitis. Expert Rev Mol Diagn 2006;6:761-6.

53. Cohen JF, Bertille N, Cohen R, Chalumeau M. Rapid antigen detection test for group A Streptococcus in children with pharyngitis. Cochrane Database Syst Rev 2016;(7):CD010502.

54. Lean WL, Arnup S, Danchin M, Steer AC. Rapid diagnostic tests for group A streptococcal pharyngitis: a metaanalysis. Pediatrics 2014;134:771-81.

55. Chiappini E, Regoli M, Bonsignori F, et al. Analysis of different recommendations from international guidelines for the management of acute pharyngitis in adults and children. Clin Ther 2011;33:48-58.

56. Chan JY, Yau F, Cheng F, Chan D, Chan B, Kwan M. Practice recommendation for the management of acute pharyngitis. Hong Kong J Paediatr 2015;20:156-62.

57. Cattoir V. Mechanisms of antibiotic resistance. In: Ferretti JJ, Stevens DL, Fischetti VA, editors. Streptococcus pyogenes: Basic Biology to Clinical Manifestations. Oklahoma City, OK: University of Oklahoma Health Sciences Center; 2016.
Available from: https:/www.ncbi.nlm.nih.gov/books/ NBK333414/. Accessed 14 Jan 2018.

58. Centre for Health Protection, Department of Health, Hong Kong SAR Government. Letter to doctor 13 June 2011: empirical antibiotic treatment of scarlet fever due to group A Streptococcus. Available from: https://www.chp.gov.hk/ files/pdf/ltd_treatment_of_gas_20110613.pdf. Accessed 14 Feb 2018.

59. Centre for Health Protection, Department of Health, Hong Kong SAR Government. Acute pharyngitis. 2017. Available from: https://www.chp.gov.hk/files/pdf/guidance_notes_ acute_pharynitis_full.pdf. Accessed 13 May 2018.

60. Altamimi S, Khalil A, Khalaiwi KA, Milner RA, Pusic MV, Al Othman MA. Short-term late-generation antibiotics versus longer term penicillin for acute streptococcal pharyngitis in children. Cochrane Database Syst Rev 2012;(8):CD004872.

61. Falagas ME, Vouloumanou EK, Matthaiou DK, Kapaskelis AM, Karageorgopoulos DE. Effectiveness and safety of short-course vs long-course antibiotic therapy for group a beta hemolytic streptococcal tonsillopharyngitis: a metaanalysis of randomized trials. Mayo Clin Proc 2008;83:8809. 